\title{
An Experiment in the Making: Inclusive Classrooms in Prison and on Campus
}

Kristin Bumiller, Amherst College

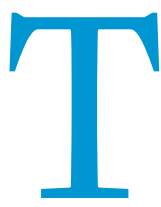
he Inside-Out teaching program provides an innovative model for conducting courses inside prisons. These courses foster dialogue between an equal number of "outside" college students and "inside" incarcerated students. Its fundamental premise is the transformative power of dialogue "across profound social differences" (Inside-Out Prison Exchange Program).

Although designed for the prison setting, the Inside-Out teaching philosophy resonates with other efforts to promote "diversity" for its potential to transform educational experiences. Teaching a diverse group of students provides an opportunity for civic engagement rarely available in a highly segregated society. Bringing together those who are held apart by inequality and discrimination creates an occasion for repair and renewal of democratic life.

As political scientists, the hope of producing these educational benefits rouses our deepest ambitions about our role in promoting a more democratic society. The benefit of a more robust exchange of views in the classroom is fundamental to the constitutional justification for diversity admission policies in institutions of higher education. As Justice Sandra Day O'Connor argued in Grutter v. Bollinger (2003, 331), the promotion of diversity in higher education serves "a fundamental role in maintaining the fabric of society."

Yet, filling a room with a different demographic profile of students on campuses or inside prisons does not in itself produce better learning outcomes. At worst, it may even reinforce preexisting inequalities among students. At best, however, it is a model for building more inclusive communities.

\section{UNSETTLING EXPECTATIONS}

Not coincidentally, I pressed forward with plans to teach courses inside a local county jail at the same time that my college launched a major initiative to increase the diversity of our student body. As concerns arose about the learning deficits of "underprepared" students, it fueled my determination to unsettle expectations about who belongs in our classrooms. Nonetheless, the Inside-Out model needed adaptations to fit into the curriculum of a highly competitive undergraduate college. In the broadest sense, my prison teaching became the means of experimenting with curricular design for inclusion and thinking about how political science courses might serve the purpose of reknitting the "fabric of society." This ongoing experiment over 10 years has forced me to confront the many complexities involved in promoting diversity, thrust me into the bureaucratic interstices of higher education and correctional institutions, and brought into my classroom the hard realities of intrusive state power.

My initial impulse, that the success of my experiment depended on my capacity to turn obstacles into assets, has served me well. An inclusive classroom makes the demographic differences-between and among prisoners and matriculated students-essential to the learning experience. It requires a concerted effort to avoid coded academic language to allow for the flow of meaningful communication. The vast range of life experience-defined by abundant privilege or extreme deprivation and everything in between-would not merely become the basis of shared experience, but rather is productively reflected in our scholarly agenda. Moreover, creating an atmosphere of equality requires designing measures of academic achievement that afford all students opportunities for success regardless of educational background.

The results show the enormous value of sustained and serious efforts to teach in a challenging setting with a diverse community of students. It also produces many examples of the difficulties in building inclusive communities in the larger context of structural inequalities and punitive social policies. Teaching inside prisons, under the gaze of the ever-present reality of state control, sharpens our awareness of these challenges.

Ultimately, this experience stimulates valuable reflection about the project of promoting diversity in higher education. Both in prisons and in colleges, the learning conditions must be scrutinized carefully, especially in regard to the educational benefits to the "disadvantaged" students. Is the sense of community an illusion? Do we maintain the integrity of academic experience? Do diverse groups of students benefit equally? Although these important questions cannot be fully addressed here, each is a reminder that teaching in either context is never far removed from the systems of social control that perpetuate group-based disadvantage.

\section{MAKE-BELIEVE}

The experiment feels the most grand at those moments in which we deny the reality of prison conditions and imagine ourselves as a cohesive community. In the beginning, it seems unlikely that close relationships will develop among students, 
given that each group never anticipated being in the same room together, much less learning as equals. However, it does not take long for students to develop a requisite degree of trust and look at one another as peers. Despite the brutality of the physical surroundings, our academic pursuits hold forth, even though the speakers are blaring ("Head count now in
Yet personal experiences inevitably and effectually make their way into class discussion-sometimes deliberately, as when we begin our exploration of citizenship and education by encouraging students in small groups to recount enormously varied early and secondary-school experiences. While such a discussion seemingly entails sharing, it also

\section{Both in prisons and in colleges, the learning conditions must be scrutinized carefully, especially in regard to educational benefits to the "disadvantaged" students. Is the sense of community an illusion? Do we maintain the integrity of academic experience? Do diverse groups of students benefit equally?}

progress"), domed cameras subject us to constant inspection, and guards walk in and out of the room. As much as we can, we hold onto it as our space and make it into a college classroom. An inside student described the classroom as feeling like "two and half hours of freedom."

Teaching in prison is adrenaline-charged; this heightens the perception of an intense and deep transformation (Scott 2013). However, the feel of make-believe must be countered with realistic expectations about what can be achieved in a single course. The atmosphere of freedom is ethereal and, as visitors, we can take it out as easily as we bring it in. Our courses are allowed inside because they can be incorporated into the agenda of prison administrators. They are promoted for their advertised effect on reducing recidivism rates and encouraging "pro-social" behavior (Erisman amd Contardo 2005). Realistically, the transformative mission stands in stark opposition to the reformist and punitive logic of prisons.

\section{SECRET KNOWLEDGE}

In every course I teach on the inside, I include in the syllabus a selection from Dewey's (1916) Democracy and Education. This text is more than an item for our discussion-it provides the philosophical foundation of our educational method. Essentially, the vision of a democratic education according to Dewey bears a strong resemblance to the justification for diversity admissions policies. Dewey $(1916,70)$ envisioned democratic education as invigorated by "wider relationships" and "free and equitable intercourse" among groups whose "interplay of experiences" cross lines of social class and status. This allows for the emergence of pragmatic knowledge that can "secure social changes" for democratic ends (Dewey 1916, 81).

Dewey asserted that the value of bringing together socially diverse groups is not for the sharing of their experiences, but rather in the hope that students with diverse experiences will challenge static and stultified thinking. This method of inquiry fits within the constraints of teaching outsiders and insiders together in a prison setting. In fact, rules set in place by correctional institutions expressly prohibit sharing of personal information by both visitors and prisoners. More to the point, the purpose of the collaboration is to avoid the stereotypes and self-identifications that stigmatize criminals and inmates. produces fine-grained analyses of the jarring discrepancies in education. At other times, sharing of personal experiences is essential to unlocking secret knowledge (Foucault 1978). This hidden knowledge, such as the extreme penalties associated with solitary confinement, cannot be found in academic materials. Rather, it emerges from firsthand accounts of the effects of isolation and how prisoners cope with these deprivations.

More vividly than any discussion in a typical classroom, students are able to express the power of the state over the individual. For example, when considering the role of the police in addressing domestic violence, it becomes clear how one's vulnerability to the discretionary action of law enforcement shapes perceptions about these interventions into private life. Whereas academic texts document the reluctance within minority communities to call the police, our discussion reveals how interfacing with the police injects new forms of violence into an already violent scene (Bumiller 2008). We learn how domestic-violence arrests are ancillary to other criminal activities when it is a charge that might stick on those already targeted or who are on probation. Often it is difficult to hear and to reconcile our classmates' strategies of police resistance which incorporate the retort, "She hit me too" in an effort to get back at the victim by triggering dual arrest.

\section{ETHNOGRAPHIC LEARNING}

Our learning is not distinct from but rather intertwined with the power structures within prisons and their impact on both professors and students. Our make-believe sense of ourselves as an integrated collectivity is routinely unmasked by events that reveal the extreme vulnerabilities of inside participants and the precariousness of our teaching experiment. The permission to teach inside is always contingent on our capacity to obey the rules even though how and when the rules will be enforced often is illusive. As sociologists have long observed, authority in prison is implemented through a militaristic structure and enhanced through its arbitrary application.

We witnessed this type of authority in action when the Prison Rape Elimination Act was newly implemented. We were told initially that because prisoners, under no conditions, could consent to physical contact, we could not touch one another-not even to shake hands. Later, handshakes 
were officially sanctioned but accompanied by the more chilling advice that any mere appearance of touch (as observed by cameras) would likely result in an investigation and our names would be posted on a public website. This advice is a potent lesson about carceral power as a form of judgment derived from a source that is all-knowing and absolute and cannot be appealed.

During volunteer training and other interactions, we are reminded with notable frequency that, as outsiders, being inside makes us possible subjects of punishment. However, my most acute concern is to assure that our presence does no harm to the insiders. Although we enter solely for an educational experience, we face the same moral dilemma as ethnographers. As guests, we hope to understand but not disrupt this unfamiliar culture.

The metaphysical power of the state (i.e., to turn classmates into inmates) is demonstrated twice during each twoand-a-half-hour period in the form of headcounts. Bracelets must be turned over and identification numbers recorded to verify that no one has escaped from the institution. The stark reality of institutional power often is exercised through the removal of inside students from our class due to disciplinary concerns and their placement in solitary confinement. At one moment, an inside student is contributing to discussion, freely speaking about his hope for social reform. Suddenly, an unknown and unspeakable violation causes his removal from our class. Inevitability, this happens near the end of the semester, after the student has become deeply invested in completing our class project. I suspect that participation in my course, which is a highly coveted privilege, puts the incarcerated men more at risk for these sanctions. These dramatic removals shatter our collective well-being; however, it is impossible for us to judge their rightness or wrongness. The person my students have gotten to know in the context of possible to bring the community that is outside of the room into the room.

In classroom exercises, students are pushed to assume the role of others: the maintenance worker who is tired and injured, the low-wage single mother who is caught between her job and taking care of her kids, and the ex-prisoner who cannot find a job. Assuming these roles enables an understanding of how power is organized within corporations and the powerlessness of at-will precarious workers. Even the most sincere attempt to "walk in someone else's shoes" does not replicate the intensity of conversations inside prison. A more diverse student body, however, makes it more likely that students know how these social realities have affected their families. As an exercise, it allows them to represent their role without being forced to share their own experiences. For others who are less familiar, these exercises bring into view the people who often are made invisible by our social architecture.

Drawing from the Inside-Out model, I also have sponsored forums for dialogue across and between unlikely groups on campus. For my course on work, we invite employees who perform a wide range of service jobs around campus to join us for an academic discussion. Employees express great reluctance to participate voluntarily. They are concerned about how they might be treated in an academic setting and are suspicious of the motivation that might accompany a temporary change in status vis-à-vis students and professor. Hearing the reservations of college employees when asked to participate in a diversity "experiment," I am reminded that the inside students enrolled in my courses are, in actuality, a captive audience. If prisoners, by definition, cannot consent, then education inside is never voluntary. The eagerness of our students and the vitality of our classes seem real-but we need to constantly remind ourselves that this reality is produced under conditions of extreme inequality.

\section{In prison, the visceral effects of power are more evident; however, in both prison and college classrooms, power operates corporeally among, between, and around us. Diverse classrooms are microcosms of social systems that perpetuate disadvantage. Rather than engage in the fantasy that these disadvantages can be suspended temporarily, it is more productive to observe and draw them into the learning experience.}

our classroom is not the person they are allowed to be in the face of institutional authority. The cultural differences are not trivial; social embeddedness in prison life produces its own distinct morality and ethics of survival.

\section{RETURNING TO CAMPUS}

During my years of teaching inside prisons, I have developed many strategies designed to reach across the social differences of two groups of students. These strategies are difficult to reproduce on college campuses. Students lack the same kind of connection and power relations are less transparent. In my course on the politics of "work," I try to simulate my in-prison teaching experience by finding every occasion

\section{REALISM}

Educating diverse groups of students creates an environment of exhilaration, intensity, and contention. In prison, the visceral effects of power are more evident; however, in both prison and college classrooms, power operates corporeally among, between, and around us. Diverse classrooms are microcosms of social systems that perpetuate disadvantage. Rather than engage in the fantasy that these disadvantages can be suspended temporarily, it is more productive to observe and draw them into the learning experience. However, it is important to ask who profits from these educational experiments. Do they provide tangible benefits for both groups of students? 
One measure of the value of diversity is that it allows for the robust exchange of views. On this score, an Inside-Out class is more successful than diversity programming on a college campus, where tensions narrow the confines of acceptable discourse about issues of identity. In prison, most outside students grant wide latitude to inside students, which creates an unfamiliar dynamic. I saw it the "day after" the 2016 presidential election, when outside students were able to consider political opinions that they perceived as linked to social circumstances (e.g., growing up in a poor rural deindustrialized area). Despite the acute divisions (i.e., my left-leaning outside students were confronted by conservative white inside students), this environment created opportunities to learn about different viewpoints that would be impossible on my college campus.

Although the openness of the dialogue is commendable, a more substantial educational benefit flows from learning about the effect of embedded circumstances in determining life chances. In Inside-Out courses, this is manifested in the fact that being a prisoner or matriculated in a college is an all-encompassing determinant of future opportunities. In recognizing our social embeddedness, students gain a greater understanding of how inequality is produced and reproduced in the United States. Throughout the semester, students realize that the causes of crime, poverty, and chronic unemployment as well as the ingredients that precede academic success, favorable careers, and formation of the ideal family are linked not only to individual characteristics, but also to the longterm effects of associations with communities, institutions, and social networks (Hagan 1993). This constant focus on the divergent opportunity structures furthers a commitment to making a positive change. Students in Inside-Out courses unite through this call for action.

Collateral gains emerge from this call for action. Some benefits already are in place when colleges and universities support Inside-Out courses: prisoners earn college credits, higher education shares resources, and students invest their social capital in prison issues. Moreover, professors overinvest their time in these courses-they quickly realize when they come face to face with a small number of the mass of incarcerated men and women that they deserve our wisdom and the fruits of our labors as much, if not more so, than the specially selected students in elite colleges.

As unsettling and productive as these teaching experiences might be, they are only a first step in promoting diversity in higher education, which requires us to look beyond the classroom at structural inequalities. Higher education reproduces inequality as long as college remains out of reach for a wide range of young people due to citizenship status, family responsibilities, disabilities, and incarceration. If our objective is to build more-inclusive communities, we must consider the limited effects of diversity programming and find new ways to expand the project. This will come, ultimately, from opening up opportunity structures more broadly for prisoners and the wide range of other deserving students excluded from our classrooms.

\section{REFERENCES}

Bumiller, Kristin. 2008. In an Abusive State. Durham, NC: Duke University Press.

Dewey, John. 1916. Democracy and Education. New York: Macmillan.

Erisman, Wendy, and Jeanne Bayer Contardo. 2005. Learning to Reduce Recidivism: A 50-State Analysis of Postsecondary Correctional Education Policy. Washington, DC: Institute for Higher Education Policy.

Foucault, Michel. 1978. The History of Sexuality. New York: Pantheon Books.

Grutterv. Bollinger. 2003.539 U.S. 306.

Hagan, John. 1993. "The Social Embeddedness of Crime and Unemployment." Criminology 31 (4): 465-91.

Inside-Out Prison Exchange Program. Available at www.insideoutcenter.org. Accessed June 12, 2018.

Scott, Robert. 2013. "Distinguishing Radical Teaching from Merely Having Intense Experiences While Teaching in Prison." Radical Teacher 95: 22-32. 